\title{
Type of stress ulcer prophylaxis and risk of nosocomial pneumonia in cardiac surgical patients: cohort study
}

\author{
(C) $(\Theta \Theta$ OPEN ACCESS
}

\author{
Brian T Bateman assistant professor ${ }^{12}$, Katsiaryna Bykov pharmacoepidemiologist ${ }^{1}$, Niteesh $\mathrm{K}$ \\ Choudhry associate professor ${ }^{1}$, Sebastian Schneeweiss professor ${ }^{1}$, Joshua J Gagne assistant \\ professor $^{1}$, Jennifer M Polinski assistant professor ${ }^{1}$, Jessica M Franklin instructor ${ }^{1}$, Michael Doherty \\ programmer $^{1}$, Michael A Fischer associate professor ${ }^{1}$, Jeremy A Rassen assistant professor ${ }^{1}$
}

${ }^{1}$ Division of Pharmacoepidemiology and Pharmacoeconomics, Department of Medicine, Brigham and Women's Hospital and Harvard Medical School, Boston, MA, USA; ${ }^{2}$ Department of Anesthesia, Critical Care, and Pain Medicine, Massachusetts General Hospital, 1620 Tremont St, Suite 3030, Boston, MA 02120, USA

\begin{abstract}
Objective To examine the relation between the type of stress ulcer prophylaxis administered and the risk of postoperative pneumonia in patients undergoing coronary artery bypass grafting.

Design Retrospective cohort study.

Setting Premier Research Database.

Participants: 21214 patients undergoing coronary artery bypass graft surgery between 2004 and 2010; 9830 (46.3\%) started proton pump inhibitors and $11384(53.7 \%)$ started $\mathrm{H}_{2}$ receptor antagonists in the immediate postoperative period.

Main outcome measure Occurrence of postoperative pneumonia, assessed using appropriate diagnostic codes.

Results Overall, 492 (5.0\%) of the 9830 patients receiving a proton pump inhibitor and 487 (4.3\%) of the 11384 patients receiving an $\mathrm{H}_{2}$ receptor antagonist developed postoperative pneumonia during the index hospital admission. After propensity score adjustment, an elevated risk of pneumonia associated with treatment with proton pump inhibitors compared with $\mathrm{H}_{2}$ receptor antagonists remained (relative risk 1.19, 95\% confidence interval 1.03 to 1.38). In the instrumental variable analysis, use of a proton pump inhibitor (compared with an $\mathrm{H}_{2}$ receptor antagonist) was associated with an increased risk of pneumonia of $8.2(95 \%$ confidence interval 0.5 to 15.9 ) cases per 1000 patients.

Conclusions Patients treated with proton pump inhibitors for stress ulcer had a small increase in the risk of postoperative pneumonia compared with patients treated with $\mathrm{H}_{2}$ receptor antagonists; this risk remained after confounding was accounted for using multiple analytic approaches.
\end{abstract}

\section{Introduction}

Nosocomial pneumonia is a common complication after cardiac surgery, affecting between $2 \%$ and $10 \%$ of patients. ${ }^{1-5}$ It carries a substantial risk of death; estimates of the mortality rate range from $20 \%$ to $50 \%{ }^{1-5}$ Therefore, identification of modifiable risk factors and strategies to prevent pneumonia following cardiac surgery are urgently needed.

Acid suppressive drugs are often used after cardiac surgery to prevent the formation of stress ulcers and gastrointestinal bleeding in these critically ill patients. These agents raise the gastrointestinal $\mathrm{pH}$, which can result in bacterial proliferation ${ }^{6-9}$; this, in turn, may predispose patients to tracheal colonization and pneumonia. ${ }^{6}{ }^{10}$ Several studies have associated acid suppressive drugs with an increased risk of pneumonia in both inpatient and outpatient settings, ${ }^{11-15}$ although results are conflicting. ${ }^{16} 17$

The two most commonly used classes of acid suppressive drugs, proton pump inhibitors and $\mathrm{H}_{2}$ receptor antagonists, may confer differential risks for pneumonia in cardiac surgical patients. A single center, retrospective study of cardiothoracic surgical patients found treatment with pantoprazole (a proton pump inhibitor) to be associated with a markedly elevated risk of nosocomial pneumonia (adjusted odds ratio 2.7, 95\% confidence interval 1.1 to 6.7) compared with ranitidine $\left(\mathrm{an}_{2}\right.$ receptor antagonist). ${ }^{10}$ This finding has not, to date, been replicated.

Given the widespread use of acid suppressive drugs in cardiac surgical patients, the importance of the complication of nosocomial pneumonia, the strong difference in risk observed in this previous study, and the remaining uncertainty about the true differential risk between these agents, we examined the 
effect of treatment with proton pump inhibitors versus $\mathrm{H}_{2}$ receptor antagonists on the risk of nosocomial pneumonia in postoperative cardiac surgical patients by using a large hospital inpatient database in the United States.

\section{Methods \\ Data source}

Study data came from the Premier Research Database, a hospital administrative database that contains information on approximately one sixth of all hospital admissions in the United States. The database contains a complete census of inpatients from approximately 500 hospitals from across the United States (numbers vary slightly by year). Preliminary analysis done by the Premier organization comparing characteristics of patients' and hospitals' for Premier hospitals with those from the National Hospital Discharge survey suggests that the profile of patients treated at Premier hospitals is similar to those treated nationally (Statement of Work Document, Premier Inc, 2012). It contains information for all patients treated at the included hospitals, independent of payer (Medicaid, Medicare, or commercial insurance). Premier collects data from member hospitals through its informatics products and then provides information back to hospitals for benchmarking purposes. Member hospitals pay Premier for these services. Member hospitals are primarily non-profit, non-governmental, community and teaching hospitals. The database includes charges for all drugs, procedures, and diagnostic tests during each hospital admission. It also includes patients' demographic characteristics and hospital characteristics, discharge diagnoses, and discharge status. Data are routinely audited, verified, and validated to ensure that the use of supplies and other hospital resources are within an acceptable range, but Premier does not directly verify that submitted data match individual patients' medical records. ${ }^{18}$ Several previous studies have used Premier data to study perioperative drug use and health outcomes. ${ }^{18-20}$

\section{Cohort}

The cohort consisted of patients aged 18 years or older who underwent the most common cardiac surgical procedure, coronary artery bypass graft surgery, identified by code 36.1 , or any subcode thereof, from ICD-9 (international classification of diseases, 9th revision) between January 1, 2004 and December 31, 2010. For the main analysis, we included only those patients who had coronary artery bypass grafting on the third day of hospital admission or thereafter. We did this to obtain a preoperative period in which to measure patients' baseline comorbidities and other risk factors; these factors may affect both the choice of agent for stress ulcer prophylaxis and risk of pneumonia and thus confound the planned analysis. To ensure that we did not include in our analysis any patients who had pneumonia at the time of admission to the hospital, we excluded those who were exposed to systemic antibiotics before the day of surgery. We also excluded patients exposed to either proton pump inhibitors or $\mathrm{H}_{2}$ receptor antagonists before the day of surgery to isolate the effect of the type of stress ulcer prophylaxis given in the immediate postoperative period. We further limited our analysis to those patients who started either a proton pump inhibitor or an $\mathrm{H}_{2}$ receptor antagonist, but not both, on postoperative days 1,2 , or both and who survived to postoperative day 3 or beyond. A single dose of acid suppressive drug is commonly administered immediately before surgery to lessen the risk of aspiration on induction of anesthesia; as the focus of this study was the risk associated with stress ulcer prophylaxis in the postoperative period, we assigned exposure status independently of the type of acid suppression drug administered on the day of surgery.

\section{Classification of drug exposure and study outcome}

We defined exposure to proton pump inhibitor by one or more charges on postoperative days 1 or 2 for omeprazole, lansoprazole, esomeprazole, pantoprazole, or rabeprazole. We defined exposure to $\mathrm{H}_{2}$ receptor antagonist by charges on postoperative days 1 or 2 for cimetidine, ranitidine, famotidine, or nizatidine.

The study outcome was the development of postoperative pneumonia during the index hospital admission and was assessed by the presence of the ICD-9 diagnosis codes of 481 to 486 or 507 (and any subcode thereof) among the reported discharge diagnoses. The exclusion of patients with systemic antibiotics before surgery would indicate that the pneumonia developed while the patient was in hospital, rather than being a condition present on admission. We also assessed two secondary outcomes: postoperative upper gastrointestinal hemorrhage and in-hospital death. We defined postoperative upper gastrointestinal hemorrhage on the basis of the presence of appropriate diagnosis and procedure codes. To ensure that any reported hemorrhage occurred postoperatively, we further required a charge for an esophagogastroduodenoscopy during the postoperative follow-up period.

Esophagogastroduodenoscopies are routinely done for diagnostic and therapeutic purposes for patients with severe upper gastrointestinal bleeding.

\section{Patient and hospital level covariates}

We extracted five groups of potential confounders from the database: demographic characteristics, surgery characteristics, chronic comorbid conditions, markers of the severity of cardiac or coexisting conditions, and hospital characteristics. The demographic characteristics considered included age on admission, ethnicity (classified as white, black, or other), marital status (classified as married, single, or unknown), and sex. Surgery characteristics included type of admission (classified as emergency, elective, or unknown); number of bypass grafts (classified as one, two, three, or four or more); whether the patient received a mammary artery graft; whether the patient had a previous coronary artery bypass graft; whether the surgery was done using cardiopulmonary bypass; whether the patient received a transfusion of packed red blood cells; whether the patient received an intra-aortic balloon pump; whether the patient received an aortic, mitral, or tricuspid value repair or replacement or ventricular aneurysm repair concurrently with their coronary artery bypass graft; and season and year of admission.

We identified the presence of chronic comorbid conditions by using discharge diagnoses including chronic hypertension, liver disease, chronic obstructive pulmonary disease and allied conditions, malignancy, previous myocardial infarction, previous stroke, endocarditis, peripheral vascular disease, chronic renal disease, chronic hemostatic disorder, smoking (either past or current), alcohol/drug misuse or dependence, carotid artery stenosis, gastrointestinal reflux, and diabetes. ${ }^{21}$ Although these conditions were recorded as discharge diagnoses, all of these conditions would have been present before admission. We also calculated the Romano modification of the Charlson comorbidity index for each patient by using conditions identified by discharge diagnoses. ${ }^{22}$ 
We evaluated markers of the severity of the patients' preoperative cardiac and coexisting disease with charges for drugs and procedures before the day of surgery. These included the use of drugs including $\beta$ blockers, calcium channel blockers, aspirin, Aggrenox or aspirin/dipyridamole, clopidogrel, statins, nitrates, fibrates, digoxin, insulin, oral anti-diabetes drugs, rhythm control drugs, warfarin, glycoprotein IIb/IIIa inhibitor, thiazide diuretics, loop diuretics, angiotensin converting enzyme inhibitors, angiotensin receptor blockers, aldosterone antagonists, direct renin inhibitors, systemic corticosteroids, inhaled steroids, leukotriene inhibitors, theophylline, inhaled $\beta_{2}$ agonists, probiotics, sucralfate, heparin, nitroglycerine, and inotropic support drugs. We also assessed charges for procedures that might indicate severity of cardiac and coexisting disease, including preoperative intensive care unit admission, cardiac resuscitation, oxygen use, telemetry, echocardiography, percutaneous angioplasty or stent, continuous positive airway pressure, mechanical ventilation, or dialysis. Finally, we determined the number of days the patient was in the hospital before surgery.

We also assessed the characteristics of the hospitals in which patients were treated. We recorded whether they were teaching hospitals and whether they were located in an urban or rural location. We estimated the annualized volume of coronary artery bypass graft surgeries performed by each hospital by dividing the total number of such surgeries for each hospital during the study time period by the number of years that each hospital performed one or more coronary artery bypass graft operations. We ranked hospitals in order of annualized volume and then categorized them into thirds of volume (high, medium, and low volume hospitals). ${ }^{23}$ We classified the region of the hospital as Midwest, Northeast, South, or West.

\section{Statistical analysis}

We determined baseline characteristics for the patients exposed to proton pump inhibitors and $\mathrm{H}_{2}$ receptor antagonists and summarized them as medians and interquartile ranges for continuous variables and counts and proportions for categorical variables. We determined the unadjusted risk and unadjusted risk ratios with $95 \%$ confidence intervals for postoperative pneumonia during the index hospital admission, comparing patients exposed to proton pump inhibitors with those exposed to $\mathrm{H}_{2}$ receptor antagonists during the defined exposure window. Because of the low event rate, we report the odds ratios from logistic regression analyses as relative risks. ${ }^{24}$

\section{Propensity score analyses}

To account for potentially important baseline differences in those patients who received proton pump inhibitors and $\mathrm{H}_{2}$ receptor antagonists, we did two separate propensity score analyses. For both analyses, we first estimated a propensity score by using a logistic regression model in which exposure to a proton pump inhibitor (as opposed to an $\mathrm{H}_{2}$ receptor antagonist) was the dependent variable and was estimated on the basis of all demographic and surgery characteristics, chronic comorbid conditions, markers of the severity of the cardiac condition, markers of coexisting disease/disease severity, and hospital characteristics, as defined above. The model predicting exposure to a proton pump inhibitor had an area under the receiver operating curve of 0.70 (possible range 0.5 to 1.0 ).

In the primary propensity score analysis, we excluded all patients with a propensity score value that corresponded to the 2.5 th centile or lower in the proton pump inhibitor exposed patients and to the 97.5th centile or higher in the $\mathrm{H}_{2}$ receptor antagonist exposed patients. This technique of trimming patients in the tails of the propensity score distribution excludes patients treated strongly contrary to expectation (for example, a patient who was strongly predicted to receive a proton pump inhibitor but received an $\mathrm{H}_{2}$ receptor antagonist instead) and thus reduces residual confounding. ${ }^{25} \mathrm{We}$ calculated tenths of propensity score among the remaining patients $(n=18573 ; 87.6 \%$ of total). We then fitted a multivariable logistic regression model including indicator of tenth of propensity score as a covariate, from which we estimated a relative risk and $95 \%$ confidence interval for postoperative pneumonia associated with proton pump inhibitor exposure.

In the second propensity score analysis, we matched patients exposed to proton pump inhibitors to those exposed to $\mathrm{H}_{2}$ receptor antagonists in a fixed 1:1 ratio by using a nearest neighbor algorithm with a maximum matching distance of 0.05 . Matching was restricted to patients undergoing coronary artery bypass grafting in the same year. After matching, the cohort included 15074 patients (71.1\% of original cohort). We again estimated a relative risk and $95 \%$ confidence interval for postoperative pneumonia.

\section{Instrumental variable analysis}

When hospitals show a strong consistency in whether they use either proton pump inhibitors or $\mathrm{H}_{2}$ receptor antagonists for prophylaxis, the decision to administer one or the other of these agents may be assumed to be made largely independently of individual patients' characteristics; in this scenario, a patient's receipt of either regimen is determined more strongly by the facility at which he or she is treated than by his or her specific risk factors. In such a circumstance, the hospital's preferred agent can act as an instrumental variable, thus setting the stage for a "natural experiment" that allows for an unbiased estimate of the risk of pneumonia, even in the presence of unmeasured confounding. ${ }^{18}{ }^{26-28}$ This analysis assumes that patients' choice of hospital is made independently of the hospital's choice of acid suppressive drug for prophylaxis, and the hospital's use of proton pump inhibitors or $\mathrm{H}_{2}$ receptor antagonists is largely independent of markers for positive or negative outcomes in that facility. We note that these assumptions, although strong, are distinct from the assumption of no residual confounding that is needed for a causal interpretation of a "conventional" analysis. A consistent result from the instrumental variable analysis may serve as a useful confirmatory analysis for our primary conventional approach.

We analyzed 15800 patients who received either a proton pump inhibitor or an $\mathrm{H}_{2}$ receptor antagonist and who were treated at hospitals that performed, on average, at least 12 coronary artery bypass graft procedures (average of one a month) during the year of surgery. We classified hospitals that administered proton pump inhibitors to $90 \%$ or more of their coronary artery bypass graft patients in a given year as hospitals with a preference for proton pump inhibitors and those that administered proton pump inhibitors to $10 \%$ or fewer of their coronary artery bypass graft patients in a given year as hospitals that prefer $\mathrm{H}_{2}$ receptor antagonists. Using the hospitals' preference as an instrumental variable, we computed differences in risk of postoperative pneumonia between the proton pump inhibitor and $\mathrm{H}_{2}$ receptor antagonist groups. We did this by using a two stage linear regression that, for robustness, also adjusted for the demographic and surgery characteristics, chronic comorbid conditions, markers of the severity of the cardiac condition, and markers of coexisting disease/disease severity. To account for any possible link between hospitals' choice of acid suppressive drug for prophylaxis and positive or negative outcomes in that 
hospital, we additionally adjusted for the hospitals' characteristics and procedure volume measurement noted above. Using Stata version 10 and the ivreg2 procedure, we estimated a risk difference and number needed to harm and their $95 \%$ confidence intervals.

\section{Secondary outcomes, exposure subgroup, and sensitivity analyses}

We repeated each of the analyses described above to examine the secondary outcomes of postoperative gastrointestinal hemorrhage and in-hospital mortality. We also compared the risk of the primary outcome in patients exposed to the most commonly prescribed $\mathrm{H}_{2}$ receptor antagonist in our cohort, famotidine, and the most commonly prescribed proton pump inhibitor, pantoprazole, to test whether the main study findings applied specifically to the most commonly used agents in each class. We did a sensitivity analysis excluding those patients who were discordant with respect to the class of acid suppressive drug received on the day of surgery and during the postoperative period (that is, patients who received an $\mathrm{H}_{2}$ receptor antagonist on the day of surgery and a proton pump inhibitor during the exposure window, or vice versa).

Lastly, we tested the generalizability of our findings to all coronary artery bypass graft patients by examining the risk of pneumonia in patients who underwent surgery on hospital day 1 and hospital day 2. Although important in establishing generalizability, estimates from these analyses are more likely to be biased than are those obtained in the primary analysis. This is due to more limited ability to control for confounding bias (as less baseline information is available on patients before surgery) and greater likelihood of misclassification bias (as patients taking a proton pump inhibitor or an $\mathrm{H}_{2}$ receptor antagonist as outpatients may switch classes on admission, but their risk of pneumonia may still be affected by the drug class they took before admission, whereas in the primary analysis a two day washout period exists for anyone exposed before admission). The propensity score for patients having surgery on day 1 included information on demographic characteristics, surgery characteristics, chronic comorbid conditions, and hospital characteristics. For patients having surgery on hospital day 2, we performed all of the exclusions that were done in the main analysis and the propensity score model included all of the covariates used in the main analysis (although measured for a shorter period). Finally, to assess the potential effects of residual confounding, we determined the strength (confounder-outcome relative risk) of a hypothetical residual confounder whose existence would produce the estimate of the effect of proton pump inhibitors on the risk of pneumonia observed in the primary analysis. ${ }^{29}$ As the effect of confounders varies with relative prevalence, we assumed a prevalence of 5\% among the unexposed patients and range of prevalences in the exposed patients.

\section{Results}

\section{Cohort characteristics}

Our primary cohort consisted of 21214 patients who had coronary artery bypass grafting between 2004 and 2010, of whom $11384(53.7 \%)$ received $\mathrm{H}_{2}$ receptor antagonists and $9830(46.3 \%)$ received proton pump inhibitors (figure $\downarrow$ ). Postoperative length of stay was the same in the two exposure groups (median 5 (interquartile range 4-7) days), thus giving us an equal opportunity to observe outcomes in both groups. The number of days of exposure to acid suppressive treatment (including the day of surgery) was similar for the two exposure groups $\left(\mathrm{H}_{2}\right.$ receptor antagonists median 6 (4-7) days; proton pump inhibitors median 6 (4-8) days). Overall, 979 (4.6\%) of patients developed postoperative pneumonia, a figure that is in line with previously published estimates. ${ }^{1-5}$ Postoperative pneumonia was strongly associated with adverse outcomes; 101 $(10.3 \%)$ of patients with postoperative pneumonia died during the index hospital admission compared with $2321.1 \%$ of patients who did not develop pneumonia. Pneumonia was also associated with substantially longer length of hospital admission (median length of stay 18 (12-29) days for patients with pneumonia versus 9 (8-12) days for those without pneumonia).

\section{Baseline characteristics}

In general, baseline characteristics were similar in patients exposed to proton pump inhibitors and $\mathrm{H}_{2}$ receptor antagonists; however, some differences existed that had the potential to confound the analysis (table $1 \Downarrow$ ). Patients exposed to proton pump inhibitors were more often white and were treated more commonly at teaching hospitals and at hospitals in the Northeast. Proton pump inhibitor exposed patients more frequently had their coronary artery bypass graft done on cardiopulmonary bypass. They more often received supplemental oxygen and monitoring with telemetry but were less often in the intensive care unit preoperatively. They received aspirin less often, but more often received intravenous heparin. After propensity score matching, these differences were no longer present. Furthermore, after propensity score matching, the proportion of patients who were mechanically ventilated was the same in the two groups $(0.7 \%)$, as was the duration of ventilation (for those who were ventilated, median 3 (2-4) days).

\section{Association of type of stress ulcer prophylaxis with postoperative pneumonia}

Overall, 492 (5.0\%) of the proton pump inhibitor exposed and 487 (4.3\%) of the $\mathrm{H}_{2}$ receptor antagonist exposed patients developed postoperative pneumonia (unadjusted relative risk ratio $1.17,95 \%$ confidence interval 1.04 to 1.32 ; risk difference per 1000 cases $7.3,1.6$ to 13.0 ). In the propensity score stratified analysis (table $2 \Downarrow$ ), the increased risk of postoperative pneumonia remained (risk ratio $1.19,1.03$ to 1.38 ). The propensity score matched analysis yielded a similar though less precise estimate (risk ratio 1.14, 0.99 to 1.32 ; risk difference $6.1,-0.6$ to 12.8 ). In the multivariable instrumental variable analysis (table $3 \Downarrow$ ), the use of proton pump inhibitors was associated with an increased absolute difference in risk of pneumonia of 8.2 (0.5 to 15.9) per 1000 patients compared with the use of $\mathrm{H}_{2}$ receptor antagonists, which corresponded to a number needed to harm of 122 (95\% confidence interval 63 to 1946). The multivariable adjusted risk ratio estimates for the most commonly used proton pump inhibitor (pantoprazole) and the most commonly used $\mathrm{H}_{2}$ receptor antagonist (famotidine) were not meaningfully different from the overall results (table $4 \Downarrow)$.

Three hundred sixty nine patients in the $\mathrm{H}_{2}$ receptor antagonist group were exposed to proton pump inhibitors on the day of surgery, and 2388 patients in the proton pump inhibitor group were exposed to $\mathrm{H}_{2}$ receptor antagonists. When we excluded these patients and repeated our primary analysis, assessing the risk of pneumonia by using propensity score stratified analysis, the results did not meaningfully change (risk ratio $1.19,1.01$ to 1.40).

In all, 69767 patients had coronary artery bypass graft surgery on hospital day 1 and were exposed to proton pump inhibitors or $\mathrm{H}_{2}$ receptor antagonists on postoperative day 1 or 2 . The 
propensity score stratified analysis suggested that proton pump inhibitors increased the risk of pneumonia in this group as well (risk ratio $1.11,1.02$ to 1.20 ). After the relevant exclusions, 25 855 patients had coronary artery bypass graft surgery on hospital day 2 and were exposed to proton pump inhibitors or $\mathrm{H}_{2}$ receptor antagonists. Again, after propensity score stratification, proton pump inhibitors were associated with an increased risk of pneumonia, albeit with a more modest effect size than that observed in our other analyses and with a confidence interval that intersected the null (risk ratio 1.06, 0.93 to 1.21).

We estimated the strength of a hypothetical residual confounder that could have produced the observed effect of proton pump inhibitors on the risk of pneumonia from the primary analysis (risk ratio 1.19). Given a prevalence of the confounder of $5 \%$ in the $\mathrm{H}_{2}$ receptor antagonist exposed population, a confounder-outcome risk ratio of 5.7 would be needed if the prevalence of the confounder in the proton pump inhibitor exposed population was $10 \%$, a risk ratio of 2.4 if the prevalence was $20 \%$, and a risk ratio of 1.8 if the prevalence was $30 \%$. The supplementary figure shows values of strength across a range of prevalence values.

\section{Association of type of stress ulcer prophylaxis with upper gastrointestinal hemorrhage and in-hospital mortality}

Overall, 154 (1.57\%) proton pump inhibitor exposed and 179 $(1.57 \%) \mathrm{H}_{2}$ receptor antagonist exposed patients died, and 16 $(0.16 \%)$ proton pump inhibitor exposed and $19(0.17 \%) \mathrm{H}_{2}$ receptor antagonist exposed patients had gastrointestinal hemorrhage requiring esophagogastroduodenoscopy. Confidence intervals for both analyses were wide and included the null (table $5 \Downarrow$ ).

\section{Discussion}

Using a hospital based cohort of 21214 patients who had coronary artery bypass graft surgery, we found a small but clinically meaningful increase in the risk of postoperative pneumonia in patients treated with proton pump inhibitors compared with those treated with $\mathrm{H}_{2}$ receptor antagonists for stress ulcer prophylaxis in the postoperative period. This increase in risk persisted despite application of several distinct techniques to identify and account for potentially confounding characteristics of patients and hospitals that might affect the selection of agent for stress ulcer prophylaxis, including the use of propensity score stratification, propensity score matching, and instrumental variable analysis. Furthermore, when we compared patients who received the most commonly administered proton pump inhibitor and $\mathrm{H}_{2}$ receptor antagonist (pantoprazole and famotidine), the observed increase in risk associated with exposure to proton pump inhibitor remained. Although the 15-19\% increase in risk of postoperative pneumonia that we observed associated with proton pump inhibitors compared with $\mathrm{H}_{2}$ receptor antagonists is small, our data favor, all other factors being equal, the selection of $\mathrm{H}_{2}$ receptor antagonists over proton pump inhibitors for stress ulcer prophylaxis in the postoperative period for coronary artery bypass graft patients.

\section{Comparison with other studies}

The magnitude of the increase in risk of pneumonia associated with proton pump inhibitors that we observed is substantially smaller than the risk found in the largest previous study that compared the risk of proton pump inhibitors versus $\mathrm{H}_{2}$ receptor antagonists in cardiothoracic surgical patients. The single center, retrospective cohort study involving 887 patients found patients treated with pantoprazole to have a remarkable 2.7-fold higher odds of pneumonia compared with those treated with ranitidine, after adjustment for confounding factors. ${ }^{10}$ Several factors may account for the difference between our study and these findings. Firstly, because the earlier study was conducted at a single center, the decision to use an a proton pump inhibitor versus an $\mathrm{H}_{2}$ receptor antagonist was likely more dependent on individual patients' characteristics, thus creating susceptibility to confounding, than it was in our large, multicenter sample in which much of the variability in selection of agent likely derived from physician/hospital guidelines or preference. Secondly, the range of patients' characteristics and comorbidities captured and adjusted for in this previous analysis was not as extensive as what we were able to capture using the Premier dataset. Finally, the $95 \%$ confidence intervals in this previous analysis were very wide (1.1 to 6.7) and intersect with the estimate of pneumonia risk associated with proton pump inhibitors versus $\mathrm{H}_{2}$ receptor antagonists in our study.

The small increase in risk of pneumonia that was observed is consistent with other studies that have examined proton pump inhibitors and $\mathrm{H}_{2}$ receptor antagonists for stress ulcer prophylaxis in critical care and general hospital settings. A recently published meta-analysis of randomized controlled clinical trials comparing the two drug classes for stress ulcer prophylaxis in critically ill patients identified seven trials with a total of 1017 patients; the point estimate for the development of nosocomial pneumonia associated with proton pump inhibitor treatment was slightly elevated, but with wide $95 \%$ confidence intervals (odds ratio $1.05,0.69$ to 1.62 ), which led the authors to conclude that there was no increase in risk. ${ }^{30}$ Similarly, in a cohort study comparing the risk of hospital acquired pneumonia associated with acid suppressive drugs compared with non-exposure to these agents, the risk estimate (compared with no stress ulcer prophylaxis) was slightly higher in the proton pump inhibitor exposed patients than in those exposed to $\mathrm{H}_{2}$ receptor antagonists (odds ratio 1.3 v 1.2). ${ }^{11}$

\section{Possible explanations and implications}

The increased risk of postoperative pneumonia associated with proton pump inhibitors versus $\mathrm{H}_{2}$ receptor antagonists is biologically plausible. Gastrointestinal bacterial overgrowth is greater in patients treated with proton pump inhibitors, ${ }^{9}$ presumably due to greater acid suppression. ${ }^{10}$ This may, in turn, predispose to microaspiration of bacterial gastrointestinal contents and pneumonia. Furthermore, evidence shows that proton pump inhibitors impair immune cell function, ${ }^{31-34}$ which is another potential mechanism to explain the differential risk that we observed. ${ }^{11}$

In our study, treatment with the two classes of acid suppressive drug was associated with similar risk of postoperative gastrointestinal hemorrhages (although, in the setting of few events, confidence intervals are wide). Randomized trials comparing proton pump inhibitors and $\mathrm{H}_{2}$ receptor antagonists in critically ill patients generally show a decrease in clinically significant bleeding associated with the use of proton pump inhibitors. ${ }^{30}$ Several conditions that are important risk factors for gastrointestinal hemorrhage are not accurately captured in the Premier database, including a history of previous gastrointestinal hemorrhage or known peptic ulcer disease; our effect estimates for this endpoint may thus be subject to residual unmeasured confounding. However, upper gastrointestinal hemorrhage was very infrequent in our cohort, and all of the affected patients were taking some form of stress ulcer prophylaxis, with an overall incidence of $0.2 \%$ based on a 
definition that required a diagnostic code indicating gastrointestinal bleeding and a charge code indicating esophagogastroduodenoscopy. Although not all gastrointestinal bleeding will result in an endoscopy (which may result in some under-ascertainment of this outcome in our study), ${ }^{35}$ hemorrhage that results in hemodynamic instability or hematemesis will generally result in an endoscopy, suggesting that our definition captures the most clinically significant bleeding events. This incidence of $0.2 \%$ contrasts with the incidence of postoperative pneumonia that we observed of $4.6 \%$. Given the substantially higher incidence of postoperative pneumonia, coupled with the fact that upper gastrointestinal bleeds are generally, in and of themselves, not lethal, ${ }^{30}{ }^{36}$ the risk of pneumonia may be the more important consideration in choosing the agent for stress ulcer prophylaxis in this patient population. This is supported by a trend toward higher mortality associated with treatment with proton pump inhibitors in our study. That said, as trial data suggest that proton pump inhibitors seem to be more effective in preventing clinically important upper gastrointestinal bleeding in critically ill patients, ${ }^{37}$ and sepsis guidelines recommend that proton pump inhibitors be used rather than $\mathrm{H}_{2}$ receptor antagonists, ${ }^{38}$ future research will need to determine how to balance the possible slightly increased risk of pneumonia associated with proton pump inhibitors compared with $\mathrm{H}_{2}$ receptor antagonists with the decreased risk of stress ulcers in specific patient populations.

\section{Limitations of study}

Our study should be interpreted in the context of the limitations inherent in its design. Although the Premier Research Database captures detailed information on inpatient drug treatment and procedure utilization, laboratory testing, and patients' diagnoses, this is administrative information collected for billing purposes and not expressly for research, and it thus lacks certain relevant clinical details. We rigorously attempted to identify and account for all relevant confounders in the available data that might influence the decision to administer a proton pump inhibitor versus an $\mathrm{H}_{2}$ receptor antagonist, but the possibility exists, as it does in all observational studies, that the results from our main analysis might be biased by unknown or unmeasured confounders. To minimize this limitation, we also did an instrumental variable analysis. In this analysis, we examined the subsample of hospitals that showed a strong preference for one or the other acid suppressive drug type (with at least $90 \%$ of patients receiving one or the other agent, presumably on the basis of a formulary or protocol), with preference acting as an instrument. The choice of agent in this circumstance is not dependent on characteristics of individual patients and is thus not subject to unmeasured confounding. The fact that the instrumental variable analysis - an analysis based on strong assumptions but different ones than the "conventional" approach-shows an increased risk of postoperative pneumonia associated with proton pump inhibitors, suggests that this association is unlikely to be a consequence of unmeasured confounding. Furthermore, the sensitivity analysis for unmeasured confounding suggested that an unmeasured confounder would need to have relatively strong associations with both proton pump inhibitor versus $\mathrm{H}_{2}$ receptor antagonist use and pneumonia to fully explain the results seen in the main analysis. However, the observed excess risk of pneumonia associated with proton pump inhibitors is very small, with confidence intervals that are very close to one, and this should be considered when interpreting these results.

An additional limitation is that we did not have access to direct clinical data such as chest radiograph findings, white blood cell counts, and sputum cultures to define the occurrence of postoperative pneumonia, but rather were dependent on the coding of this complication in the discharge abstract. The specificity for the recording of pneumonia in administrative data seems to be high (although these validations studies did not specifically examine postoperative pneumonia). ${ }^{39} 40$

Furthermore, any misclassification of the outcome is likely to be non-differential between the two groups, such that our relative risk estimates would be biased, if anything, to the null.

Under-coding or misclassification is thus unlikely to be able to account for the increased risk associated with proton pump inhibitors that we observed.

A further limitation is that, to establish baseline measures of comorbidities that might affect the decision to administer a proton pump inhibitor or an $\mathrm{H}_{2}$ receptor antagonist, we did our primary analysis on those patients who had surgery on hospital day 3 or later. To ensure that the diagnosis of pneumonia occurred during the postoperative period, we further excluded patients who were exposed to antibiotics before surgery (which might be used to treat pneumonia if diagnosed preoperatively). We also excluded patients exposed to acid suppressive drugs before the day of surgery to isolate the effect of these drugs as administered in the immediate postoperative period. While recognizing that our effect estimates are more likely to be subject to bias than are those of the main analysis, we also examined the risk of pneumonia associated with exposure to proton pump inhibitors in patients who had surgery on hospital day 1 or 2 . In both of these analyses, proton pump inhibitors were again associated with increased risk of pneumonia, suggesting that our results are generalizable to all coronary artery bypass graft patients. That said, the estimates of the effect of proton pump inhibitors on the risk of pneumonia for patients who had coronary artery bypass graft surgery on hospital days 1 or 2 were closer to the null than was observed in the primary analysis (which may be a result of residual confounding of the estimate, greater exposure misclassification among patients with surgery earlier in the hospital admission (owing to exposure before admission), or effect modification by timing of surgery).

\section{Conclusion}

Our analysis suggests a $15-19 \%$ increase in the risk of postoperative pneumonia associated with the administration of proton pump inhibitors compared with $\mathrm{H}_{2}$ receptor antagonists in the immediate postoperative period in coronary artery bypass graft patients. Given the importance of the complication of postoperative pneumonia in this patient population, clinicians should consider this differential risk when selecting the type of agent used for stress ulcer prophylaxis.

Contributors: BTB and KB were involved in all parts of the study. JAR was involved in designing the study, data analysis, and writing the manuscript. MD was involved in data analysis and revising the manuscript. NKC, SS, JJG, JMP, JMF, and MAF were involved in designing the study and revising the manuscript. BTB and KB are the guarantors.

Funding source: JAR is a recipient of a career development award from the Agency for Healthcare Research and Quality (K01 HS018088).

Competing interests: All authors have completed the ICMJE uniform disclosure form at www.icmje.org/coi_disclosure.pdf (available on request from the corresponding author) and declare: SS is principal investigator of the Brigham and Women's Hospital DEcIDE Center on Comparative Effectiveness Research and the DEcIDE Methods Center, both funded by the Agency for Healthcare Research and Quality, and of the Harvard-Brigham Drug Safety and Risk Management Research Center funded by the Food and Drug Administration; SS is a paid 


\section{What is already known on this topic}

Each year, approximately 800000 patients have coronary artery bypass graft surgery (CABG) worldwide, making it one of the most commonly performed operative procedures

Proton pump inhibitors and $\mathrm{H}_{2}$ receptor antagonists are acid suppressing agents that are frequently administered after $C A B G$ for stress ulcer prophylaxis

Postoperative pneumonia is a common and highly morbid complication following CABG

\section{What this study adds}

A small elevation in the risk of pneumonia was associated with treatment with proton pump inhibitors compared with $\mathrm{H}_{2}$ receptor antagonists in CABG patients

This risk remained after the use of multiple analytic approaches to account for confounding

consultant to WHISCON LLC and Booz \& Co, and he is principal investigator of investigator initiated grants to the Brigham and Women's Hospital from Pfizer, Novartis, and Boehringer-Ingelheim unrelated to the topic of this study; JAR is a paid consultant to WHISCON LLC; no other relationships or activities that could appear to have influenced the submitted work.

Ethical approval: The use of this dataset for research was approved by the institutional review board (\#2011P002580) of the Brigham and Women's Hospital, Boston, MA and a data use agreement was in place. Data sharing: No additional data available.

1 Kollef MH, Sharpless L, Vlasnik J, Pasque C, Murphy D, Fraser VJ. The impact of nosocomial infections on patient outcomes following cardiac surgery. Chest 1997;112:666-75.

2 Leal-Noval SR, Marquez-Vacaro JA, Garcia-Curiel A, Camacho-Larana P, Rincon-Ferrari $M D$, Ordonez-Fernandez A, et al. Nosocomial pneumonia in patients undergoing heart surgery. Crit Care Med 2000;28:935-40.

3 Hortal J, Munoz P, Cuerpo G, Litvan H, Rosseel PM, Bouza E. Ventilator-associated pneumonia in patients undergoing major heart surgery: an incidence study in Europe. Crit Care 2009;13:R80.

4 Bouza E, Perez A, Munoz P, Jesus Perez M, Rincon C, Sanchez C, et al. Ventilator-associated pneumonia after heart surgery: a prospective analysis and the value of surveillance. Crit Care Med 2003;31:1964-70.

5 Pawar M, Mehta Y, Khurana P, Chaudhary A, Kulkarni V, Trehan N. Ventilator-associated pneumonia: incidence, risk factors, outcome, and microbiology. J Cardiothorac Vasc Anesth 2003;17:22-8

6 Du Moulin GC, Paterson DG, Hedley-Whyte J, Lisbon A. Aspiration of gastric bacteria in antacid-treated patients: a frequent cause of postoperative colonisation of the airway. Lancet 1982;1:242-5.

7 Donowitz LG, Page MC, Mileur BL, Guenthner SH. Alteration of normal gastric flora in critical care patients receiving antacid and cimetidine therapy. Infect Control 1986;7:23-6.

8 Driks MR, Craven DE, Celli BR, Manning M, Burke RA, Garvin GM, et al. Nosocomial pneumonia in intubated patients given sucralfate as compared with antacids or histamine type 2 blockers: the role of gastric colonization. N Engl J Med 1987;317:1376-82.

9 Thorens J, Froehlich F, Schwizer W, Saraga E, Bille J, Gyr K, et al. Bacterial overgrowth during treatment with omeprazole compared with cimetidine: a prospective randomised double blind study. Gut 1996;39:54-9.

10 Miano TA, Reichert MG, Houle TT, MacGregor DA, Kincaid EH, Bowton DL. Nosocomial pneumonia risk and stress ulcer prophylaxis: a comparison of pantoprazole vs ranitidine in cardiothoracic surgery patients. Chest 2009;136:440-7.

11 Herzig SJ, Howell MD, Ngo LH, Marcantonio ER. Acid-suppressive medication use and the risk for hospital-acquired pneumonia. JAMA 2009;301:2120-8.

12 Gulmez SE, Holm A, Frederiksen H, Jensen TG, Pedersen C, Hallas J. Use of proton pump inhibitors and the risk of community-acquired pneumonia: a population-based case-control study. Arch Intern Med 2007;167:950-5.

13 Laheij RJ, Sturkenboom MC, Hassing RJ, Dieleman J, Stricker BH, Jansen JB. Risk of community-acquired pneumonia and use of gastric acid-suppressive drugs. JAMA 2004:292:1955-60.

14 Sarkar M, Hennessy S, Yang YX. Proton-pump inhibitor use and the risk for community-acquired pneumonia. Ann Intern Med 2008;149:391-8.

15 Rodriguez LA, Ruigomez A, Wallander MA, Johansson S. Acid-suppressive drugs and community-acquired pneumonia. Epidemiology 2009;20:800-6.

16 Redelmeier DA, McAlister FA, Kandel CE, Lu H, Daneman N. Postoperative pneumonia in elderly patients receiving acid suppressants: a retrospective cohort analysis. BMJ 2010;340:c2608

17 Beaulieu M, Williamson D, Sirois C, Lachaine J. Do proton-pump inhibitors increase the risk for nosocomial pneumonia in a medical intensive care unit? J Crit Care 2008:23:513-8.

18 Schneeweiss S, Seeger JD, Landon J, Walker AM. Aprotinin during coronary-artery bypass grafting and risk of death. N Engl J Med 2008;358:771-83.

19 Lindenauer PK, Pekow P, Wang K, Gutierrez B, Benjamin EM. Lipid-lowering therapy and in-hospital mortality following major noncardiac surgery. JAMA 2004;291:2092-9.
20 Lindenauer PK, Pekow P, Wang K, Mamidi DK, Gutierrez B, Benjamin EM. Perioperative beta-blocker therapy and mortality after major noncardiac surgery. $N$ Engl $J$ Med 2005;353:349-61.

21 Elixhauser A, Steiner C, Harris DR, Coffey RM. Comorbidity measures for use with administrative data. Med Care 1998:36:8-27.

22 Romano PS, Roos LL, Jollis JG. Adapting a clinical comorbidity index for use with ICD-9-CM administrative data: differing perspectives. J Clin Epidemiol 1993;46:1075-9, discussion 81-90.

23 Kulik A, Brookhart MA, Levin R, Ruel M, Solomon DH, Choudhry NK. Impact of statin use on outcomes after coronary artery bypass graft surgery. Circulation 2008;118:1785-92.

24 Rothman KJ, Greenland S, Lash TL. Modern epidemiology. 3rd ed. Wolters Kluwer Health/Lippincott Williams \& Wilkins, 2008.

25 Sturmer T, Rothman KJ, Avorn J, Glynn RJ. Treatment effects in the presence of unmeasured confounding: dealing with observations in the tails of the propensity score distribution-a simulation study. Am J Epidemiol 2010;172:843-54.

26 Rassen JA, Schneeweiss S, Glynn RJ, Mittleman MA, Brookhart MA. Instrumental variable analysis for estimation of treatment effects with dichotomous outcomes. Am J Epidemio 2009;169:273-84.

27 Brookhart MA, Wang PS, Solomon DH, Schneeweiss S. Instrumental variable analysis of secondary pharmacoepidemiologic data. Epidemiology 2006;17:373-4.

28 Brookhart MA, Rassen JA, Schneeweiss S. Instrumental variable methods in comparative safety and effectiveness research. Pharmacoepidemiol Drug Saf 2010;19:537-54.

29 Schneeweiss S. Sensitivity analysis and external adjustment for unmeasured confounders in epidemiologic database studies of therapeutics. Pharmacoepidemiol Drug Saf 2006;15:291-303.

30 Barkun AN, Bardou M, Pham CQ, Martel M. Proton pump inhibitors vs. histamine 2 receptor antagonists for stress-related mucosal bleeding prophylaxis in critically ill patients: a meta-analysis. Am J Gastroenterol 2012;107:507-20.

31 Aybay C, Imir T, Okur $\mathrm{H}$. The effect of omeprazole on human natural killer cell activity. Gen Pharmacol 1995;26:1413-8.

32 Capodicasa E, De Bellis F, Pelli MA. Effect of lansoprazole on human leukocyte function Immunopharmacol Immunotoxicol 1999;21:357-77.

33 Zedtwitz-Liebenstein K, Wenisch C, Patruta S, Parschalk B, Daxbock F, Graninger W. Omeprazole treatment diminishes intra- and extracellular neutrophil reactive oxygen production and bactericidal activity. Crit Care Med 2002;30:1118-22.

34 Kedika RR, Souza RF, Spechler SJ. Potential anti-inflammatory effects of proton pump inhibitors: a review and discussion of the clinical implications. Dig Dis Sci 2009:54:2312-7.

35 Lin S, Konstance R, Jollis J, Fisher DA. The utility of upper endoscopy in patients with concomitant upper gastrointestinal bleeding and acute myocardial infarction. Dig Dis Sci 2006;51:2377-83.

36 Lau JY, Leung WK, Wu JC, Chan FK, Wong VW, Chiu PW, et al. Omeprazole before endoscopy in patients with gastrointestinal bleeding. N Engl J Med 2007;356:1631-40.

37 Alhazzani W, Alenezi F, Jaeschke RZ, Moayyedi P, Cook DJ. Proton pump inhibitors versus histamine 2 receptor antagonists for stress ulcer prophylaxis in critically ill patients: a systematic review and meta-analysis. Crit Care Med 2013;41:693-705.

38 Dellinger RP, Levy MM, Rhodes A, Annane D, Gerlach H, Opal SM, et al. Surviving sepsis campaign: international guidelines for management of severe sepsis and septic shock: 2012. Crit Care Med 2013;41:580-637.

39 Aronsky D, Haug PJ, Lagor C, Dean NC. Accuracy of administrative data for identifying patients with pneumonia. Am J Med Qual 2005;20:319-28.

40 Skull SA, Andrews RM, Byrnes GB, Campbell DA, Nolan TM, Brown GV, et al. ICD-10 codes are a valid tool for identification of pneumonia in hospitalized patients aged $>$ or $=$ 65 years. Epidemiol Infect 2008;136:232-40.

Accepted: 20 August 2013

\section{Cite this as: BMJ 2013;347:f5416}

This is an Open Access article distributed in accordance with the Creative Commons Attribution Non Commercial (CC BY-NC 3.0) license, which permits others to distribute, remix, adapt, build upon this work non-commercially, and license their derivative works on different terms, provided the original work is properly cited and the use is non-commercial. See: http://creativecommons.org/licenses/by-nc/3.0/. 


\section{Tables}

Table 1| Selected baseline characteristics of study patients treated with either proton pump inhibitors (PPI) or H2 receptor antagonists (H2RA) for stress ulcer prophylaxis after coronary artery bypass grafting. Values are numbers (percentages) unless stated otherwise

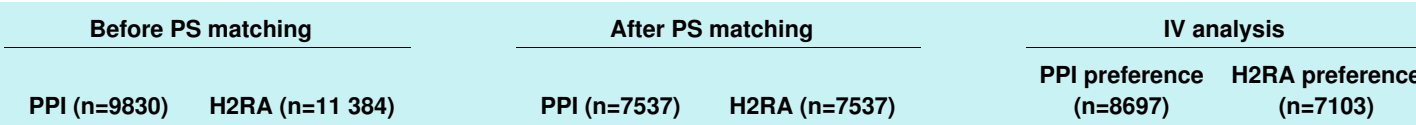

Demographic characteristics

\begin{tabular}{|c|c|c|c|c|c|c|}
\hline Median (IQR) age & $66.0(58.0-74.0)$ & $66.0(57.0-74.0)$ & $66.0(58.0-74.0)$ & $66.0(58.0-74.0)$ & $66.0(57.0-74.0)$ & $66.0(58.0-74.0)$ \\
\hline \multicolumn{7}{|l|}{ Ethnicity: } \\
\hline White & $7318(74.4)$ & $7896(69.4)$ & $5441(72.2)$ & $5422(71.9)$ & $5970(68.6)$ & $5383(75.8)$ \\
\hline Black & $573(5.8)$ & $850(7.5)$ & $490(6.5)$ & $482(6.4)$ & $684(7.9)$ & $396(5.6)$ \\
\hline Other & $387(3.9)$ & $556(4.9)$ & $336(4.5)$ & $338(4.5)$ & $427(4.9)$ & $276(3.9)$ \\
\hline Female sex & $2516(25.6)$ & $3114(27.4)$ & $1968(26.1)$ & $1999(26.5)$ & $2462(28.3)$ & $1766(24.9)$ \\
\hline \multicolumn{7}{|l|}{ Surgical characteristics } \\
\hline \multicolumn{7}{|l|}{ Type of admission: } \\
\hline Emergency & 7064 (71.9) & $7796(68.5)$ & $5234(69.4)$ & $5281(70.1)$ & $5905(67.9)$ & $5077(71.5)$ \\
\hline Elective & $2699(27.5)$ & $3504(30.8)$ & $2261(30.0)$ & 2207 (29.3) & $2719(31.3)$ & $1970(27.7)$ \\
\hline Unknown & $67(0.7)$ & $84(0.7)$ & $42(0.6)$ & $49(0.7)$ & $73(0.8)$ & $56(0.8)$ \\
\hline $\begin{array}{l}\text { Surgery done with } \\
\text { cardiopulmonary } \\
\text { bypass }\end{array}$ & $8460(86.1)$ & 9093 (79.9) & $6294(83.5)$ & $6264(83.1)$ & $6877(79.1)$ & $6154(86.6)$ \\
\hline \multicolumn{7}{|l|}{ Comorbidities } \\
\hline $\begin{array}{l}\text { Median (IQR) } \\
\text { Charlson comorbidity } \\
\text { score }\end{array}$ & $2.0(1.0-3.0)$ & $2.0(1.0-3.0)$ & $2.0(1.0-3.0)$ & $2.0(1.0-3.0)$ & $2.0(1.0-3.0)$ & $2.0(1.0-3.0)$ \\
\hline Chronic hypertension & 7599 (77.3) & $8921(78.4)$ & $5902(78.3)$ & $5893(78.2)$ & $6875(79.1)$ & $5466(77.0)$ \\
\hline $\begin{array}{l}\text { Chronic obstructive } \\
\text { pulmonary disease } \\
\text { and allied conditions }\end{array}$ & $2153(21.9)$ & $2662(23.4)$ & $1664(22.1)$ & $1709(22.7)$ & 2078 (23.9) & $1547(21.8)$ \\
\hline $\begin{array}{l}\text { Previous myocardial } \\
\text { infarction }\end{array}$ & $1544(15.7)$ & $1722(15.1)$ & $1168(15.5)$ & $1167(15.5)$ & $1335(15.4)$ & $1138(16.0)$ \\
\hline Chronic renal disease & $1074(10.9)$ & $929(8.2)$ & $739(9.8)$ & $746(9.9)$ & $716(8.2)$ & $800(11.3)$ \\
\hline Diabetes & $3988(40.6)$ & $4721(41.5)$ & $3095(41.1)$ & $3084(40.9)$ & $3633(41.8)$ & $2921(41.1)$ \\
\hline \multicolumn{7}{|c|}{ Inpatient use of drugs and services before surgery } \\
\hline$\beta$ blocker & $8392(85.4)$ & $9511(83.5)$ & $6372(84.5)$ & $6407(85.0)$ & $7223(83.1)$ & $6087(85.7)$ \\
\hline Aspirin & $6830(69.5)$ & $8442(74.2)$ & $5424(72.0)$ & $5456(72.4)$ & 6545 (75.3) & $4848(68.3)$ \\
\hline Clopidogrel & $1642(16.7)$ & $2012(17.7)$ & $1307(17.3)$ & $1300(17.2)$ & 1585 (18.2) & 1169 (16.5) \\
\hline Statin & $7496(76.3)$ & $8214(72.2)$ & $5642(74.9)$ & $5641(74.8)$ & $6270(72.1)$ & $5518(77.7)$ \\
\hline Nitrates & $5818(59.2)$ & $6916(60.8)$ & $4495(59.6)$ & $4534(60.2)$ & $5216(60.0)$ & $4156(58.5)$ \\
\hline Insulin & $2811(28.6)$ & $2959(26.0)$ & $2055(27.3)$ & $2060(27.3)$ & $2200(25.3)$ & $2073(29.2)$ \\
\hline $\begin{array}{l}\text { Oral anti-diabetes } \\
\text { drugs }\end{array}$ & 3330 (33.9) & $3731(32.8)$ & $2516(33.4)$ & 2503 (33.2) & $2816(32.4)$ & $2450(34.5)$ \\
\hline $\begin{array}{l}\text { Angiotensin converting } \\
\text { enzyme inhibitor }\end{array}$ & $4623(47.0)$ & $5391(47.4)$ & $3574(47.4)$ & 3595 (47.7) & 4078 (46.9) & $3387(47.7)$ \\
\hline Inhaled $\beta_{2}$ agonists & $1004(10.2)$ & $1216(10.7)$ & $794(10.5)$ & $789(10.5)$ & $912(10.5)$ & $733(10.3)$ \\
\hline Intravenous heparin & $5008(50.9)$ & $4930(43.3)$ & $3518(46.7)$ & $3552(47.1)$ & 3768 (43.3) & $3810(53.6)$ \\
\hline $\begin{array}{l}\text { Intravenous } \\
\text { nitroglycerin }\end{array}$ & 2192 (22.3) & 3066 (26.9) & $1862(24.7)$ & $1866(24.8)$ & $2357(27.1)$ & $1504(21.2)$ \\
\hline Intravenous inotropes & $909(9.2)$ & $858(7.5)$ & $602(8.0)$ & $613(8.1)$ & $605(7.0)$ & $589(8.3)$ \\
\hline $\begin{array}{l}\text { Intensive care unit } \\
\text { admission }\end{array}$ & $4692(47.7)$ & 6369 (55.9) & 3827 (50.8) & $3850(51.1)$ & $4844(55.7)$ & $3347(47.1)$ \\
\hline Cardiac resuscitation & $34(0.3)$ & $52(0.5)$ & $26(0.3)$ & $26(0.3)$ & $35(0.4)$ & $24(0.3)$ \\
\hline Echocardiography & $4067(41.4)$ & $4563(40.1)$ & 3057 (40.6) & $3115(41.3)$ & 3460 (39.8) & $3019(42.5)$ \\
\hline
\end{tabular}


Table 1 (continued)

\begin{tabular}{|c|c|c|c|c|c|c|}
\hline & \multicolumn{2}{|c|}{ Before PS matching } & \multicolumn{2}{|c|}{ After PS matching } & \multicolumn{2}{|c|}{ IV analysis } \\
\hline & PPI (n=9830) & H2RA ( $n=11$ 384) & PPI (n=7537) & H2RA (n=7537) & $\begin{array}{l}\text { PPI preference } \\
\quad(n=8697)\end{array}$ & $\begin{array}{l}\text { H2RA preference } \\
(n=7103)\end{array}$ \\
\hline Mechanical ventilation & $60(0.6)$ & $79(0.7)$ & $50(0.7)$ & $49(0.7)$ & $63(0.7)$ & $42(0.6)$ \\
\hline Dialysis & $146(1.5)$ & $153(1.3)$ & $107(1.4)$ & $113(1.5)$ & $123(1.4)$ & $95(1.3)$ \\
\hline \multicolumn{7}{|c|}{ Hospital characteristics } \\
\hline Teaching hospital & $5798(59.0)$ & $5566(48.9)$ & 4007 (53.2) & 4014 (53.3) & $4128(47.5)$ & $4387(61.8)$ \\
\hline Urban hospital & $9036(91.9)$ & 10614 (93.2) & $6955(92.3)$ & $6954(92.3)$ & $8099(93.1)$ & $6584(92.7)$ \\
\hline
\end{tabular}

IQR=interquartile range; IV=instrumental variable; $P S=$ propensity score.

Age was modeled as categorical variable in propensity score/instrumental variable models. Additional covariates that were included in propensity score/instrumental variable models and balanced after matching include marriage status; number of grafts; previous coronary artery bypass graft (CABG); mammary graft; packed red blood cell transfusion; intra-aortic balloon pump placement; aortic, mitral, or tricuspid valve replacement or repair; ventricular aneurysm repair; chronic liver disease; cancer; previous stroke; previous endocarditis; peripheral vascular disease; chronic hemostatic disorder; smoking; alcohol or drug misuse; carotid artery stenosis; gastroesophageal reflux disease; calcium channel blockers; aspirin/dipyridamole; fibrates; digoxin; rhythm control drugs; warfarin; glycoprotein Ilb/Illa inhibitor; thiazide diuretics; loop diuretics; angiotensin receptor blockers; aldosterone antagonists; direct renin inhibitor; systemic steroids; inhaled steroids; leukotriene inhibitors; theophylline; probiotics; sucralfate; oxygen use; telemetry; percutaneous angioplasty or stent; continuous positive airway pressure; preoperative length of stay; third of CABG volume; and region. 
Table 2| Relative risk of postoperative pneumonia in patients undergoing coronary artery bypass graft surgery treated with proton pump inhibitors (PPI) compared with $\mathrm{H} 2$ receptor antagonists (H2RA)

\begin{tabular}{|c|c|c|c|c|}
\hline \multirow[b]{2}{*}{ Analysis } & \multicolumn{2}{|c|}{ No of outcomes/No of patients } & \multirow[b]{2}{*}{ Risk ratio $(95 \% \mathrm{Cl})$} & \multirow[b]{2}{*}{ Risk difference $(95 \% \mathrm{Cl})$ per 1000 patients } \\
\hline & PPI & H2RA & & \\
\hline Unadjusted & $492 / 9830$ & $487 / 11384$ & 1.17 (1.04 to 1.32$)$ & $7.3(1.6$ to 13.0$)$ \\
\hline Age, sex, race, calendar year adjusted & $492 / 9830$ & $487 / 11384$ & $1.19(1.04$ to 1.36$)$ & - \\
\hline Propensity score tenths stratified & $411 / 8514$ & $421 / 10059$ & 1.19 (1.03 to 1.38$)$ & - \\
\hline Propensity score matched & $369 / 7537$ & $323 / 7537$ & $1.14(0.99$ to 1.32$)$ & $6.1(-0.6$ to 12.8$)$ \\
\hline
\end{tabular}


Table 3| Instrumental variable estimates of risk differences of postoperative pneumonia for patients treated with proton pump inhibitors compared with $\mathrm{H} 2$ receptor antagonists

Model

Risk difference per 1000 patients $(95 \% \mathrm{Cl})$

Crude model

$7.0(0.2$ to 13.9$)$

Age, sex, race, calendar year adjusted model

$8.2(1.1$ to 15.4$)$

Propensity score tenths adjusted model

$8.2(0.5$ to 15.9$)$ 
Table 4| Relative risk of postoperative pneumonia in patients undergoing coronary artery bypass graft surgery treated with pantoprazole compared with famotidine

\begin{tabular}{lccccc} 
& \multicolumn{2}{c}{ No of outcomes/No of patients } & & \\
\cline { 2 - 3 } Analysis & Pantoprazole & Famotidine & Risk ratio (95\% Cl) & Risk difference $(\mathbf{9 5 \%}$ Cl) per 1000 patients \\
Unadjusted & $350 / 7295$ & $448 / 10253$ & $1.10(0.96$ to 1.26$)$ & $4.3(-2.0$ to 10.6$)$ \\
\hline Age, sex, race, calendar year adjusted & $350 / 7295$ & $448 / 10253$ & $1.13(0.97$ to 1.30$)$ & - \\
\hline Propensity score tenths stratified & $293 / 6243$ & $391 / 9157$ & $1.15(0.98$ to 1.35$)$ & - \\
\hline Propensity score matched & $290 / 5931$ & $250 / 5931$ & $1.16(0.98$ to 1.37$)$ & $6.7(-0.8$ to 14.2$)$ \\
\hline
\end{tabular}


Table 5| Relative risk of postoperative gastrointestinal hemorrhage and in-hospital mortality in patients undergoing coronary artery bypass graft surgery treated with proton pump inhibitors (PPI) compared with H2 receptor antagonists (H2RA)

\begin{tabular}{|c|c|c|c|c|}
\hline \multirow[b]{2}{*}{ Outcome and analysis } & \multicolumn{2}{|c|}{ No of outcomes/No of patients } & \multirow[b]{2}{*}{ Risk ratio $(95 \% \mathrm{Cl})$} & \multirow{2}{*}{$\begin{array}{c}\text { Risk difference }(95 \% \mathrm{Cl}) \text { per } 1000 \\
\text { patients }\end{array}$} \\
\hline & PPI & H2RA & & \\
\hline \multicolumn{5}{|c|}{ Gastrointestinal bleed with esophagogastroduodenoscopy: } \\
\hline Unadjusted & $16 / 9830$ & $19 / 11384$ & $0.98(0.50$ to 1.90$)$ & $0(-1.1$ to 1.1$)$ \\
\hline Age, sex, race, calendar year adjusted & $16 / 9830$ & $19 / 11384$ & $1.05(0.53$ to 2.08$)$ & - \\
\hline Propensity score tenths stratified & $14 / 8514$ & $18 / 10059$ & $0.96(0.46$ to 2.01$)$ & - \\
\hline Propensity score matched & $13 / 7537$ & $10 / 7537$ & $1.30(0.57$ to 2.96$)$ & $0.4(-0.8$ to 1.6$)$ \\
\hline \multicolumn{5}{|l|}{ Death: } \\
\hline Unadjusted & $154 / 9830$ & $179 / 11384$ & $1.00(0.81$ to 1.23$)$ & $-0.1(-3.4$ to3.3) \\
\hline Age, sex, race, calendar year adjusted & $154 / 9830$ & $179 / 11384$ & $1.09(0.87$ to 1.36$)$ & - \\
\hline Propensity score tenths stratified & $134 / 8514$ & $150 / 10059$ & $1.15(0.90$ to 1.47$)$ & - \\
\hline Propensity score matched & $126 / 7537$ & $116 / 7537$ & $1.09(0.85$ to 1.40$)$ & $1.3(-2.7$ to 5.3$)$ \\
\hline
\end{tabular}




\section{Figure}

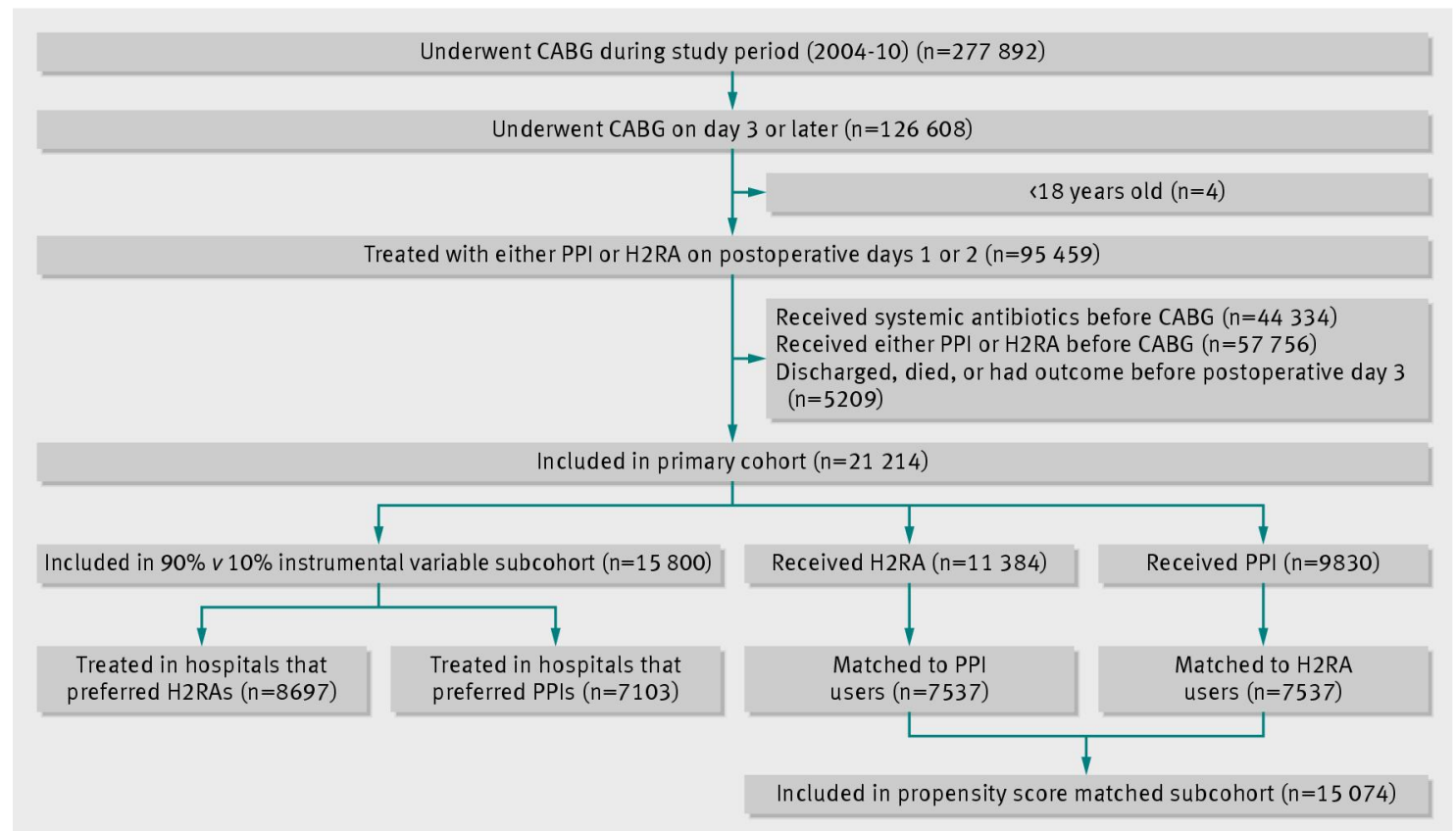

Flow of patients through study. $\mathrm{CABG}=$ coronary artery bypass graft; $\mathrm{H} 2 \mathrm{RA}=\mathrm{H}_{2}$ receptor antagonist; $\mathrm{PPI}=$ proton pump inhibitor. 